\title{
Investigating Talent Management Philosophies
}

\section{- Urbancová Hana, Vnoučková Lucie}

\begin{abstract}
This study, motivated by the recognition that organizational performance and success always hinges on employee competencies and management's skill in utilizing their potentials, focuses on one of the key factors in organizational efficiency: the possibilities of development of talented employees within Czech organizations. The data was collected via two quantitative studies. The first study involved 100 organizations from every economic sector with a main focus on the topic from the organization's perspective. The second study explored the approach from employees' perspective. Our analysis shows that different talent management philosophies are used in practice. Almost half of the sample use inclusive and stable philosophy, $11 \%$ inclusive and developable philosophy and almost $10 \%$ exclusive and developable philosophy. Employees are mostly developed in generally recommended areas without any consideration for the specific individual's characteristics or related opportunities. It is a stable approach. Limitations of this study may be found in the focus on analysis outcomes - on practitioners in particular. The present findings provide a basis for future hypotheses and research in this area.
\end{abstract}

Keywords: Cžech Republic, competencies, development, employee, organization, talent

JEL Classification: J6, M12, M54

\section{INTRODUCTION}

Organizations that recognize and react to employee needs to find that utilizing employee potentials makes it likely to increase productivity (Scullion et al., 2010; Linhartová \& Urbancová, 2012; Vnoučková, 2014). Supporting employee career growth builds employer brands (Despande, 2010; Königová \& Urbancová 2013; Chhabra \& Shama, 2014), making the organization more attractive to potential hires. Employees become the organization's key capital, and must be supported (Becker \& Gerhart, 1996). Both individuals and organizations utilize employee development to meet their goals, the potential for which hinges upon possessing quality employees (Gelens et al., 2014).

Talented people are rare and in demand. Many people are out of a job in the Czech Republic due to economic crisis (Czech Statistical Office data shows average unemployment at 7.4\%), constantly in search of opportunities. Highly talented people have better opportunity; organizations appreciate talented employees. Success lies not simply in getting talented employees, but in keeping them, too (Urbancová, 2012). They know their worthness and know they can move to another position or organization (Seibert et al., 2001; Sonnenberg et al., 2014).

The current economic crisis has a drawback effect on the number of new products, services, and patents; the effect extended to cuts on research and development funding and spending. This has significantly deterred talented employees; they seem to have been less motivated to keep working for organizations whose production and services have been cut to the bare minimum and 
show no interest in R\&D. This is because employees know that they can develop their potential no further in this setting. As a consequence, they leave the organization. This should act as a driver for organizations to think carefully about where to scale back, Targeting the development of talented employees is in fact a key success factor for organizations, therefore an area worth researching (Farndale et al., 2010).

This article aims to identify and evaluate the preferences of Czech employees and organizations for talent management philosophies. It further aims to compare these preferences and to propose an effective strategy for the organization to acquire key talent management competencies.

The paper is composed of five sections. The first is a literature review, this followed by a presentation of our methodological approach. Subsequently, an analysis and discussion section comes before our recommendations. Finally, we conclude the paper and summarize the contributions and limitations of the study.

\subsection{THEORETICAL BACKGROUND}

Talent development is an essential part of progressive care for employees: developing people with their own ability to be creative, to experience, to gain knowledge, and who have the will to work at a particular motivational level (Zahorsky, 2010). Unless employees' desire to learn, improve, and feel at the top of their game is fulfilled, they may consider leaving the organization (Katcher \& Snyder, 2009; Vnoučková, 2013; Abbas et al., 2014). This care provided by organizations must target expanding employee professional readiness and increase education levels as well as impact lifestyle (Walker, 1999; Lewis \& Heckman, 2006). In the same vein, people's existence within an organization must be understood in the context of all their social ties in which individual characteristics are reflected and an effort made to self-improve both the personal and social dimensions (Burt, 1997; Adler \& Kwon, 2002).

Academic research has highlighted two different focuses on employees talents, these are: (1) Talent concerns only managerial positions (key employees - "exclusive focus") (Boudreau \& Ramstad, 2005; Smilansky, 2005; Joyce \& Slocum, 2012), or (2) any capable employee contributing to fulfilling the organization's tasks - "inclusive focus" (Buckingham \& Vosburgh, 2001; Yost \& Chang, 2009; Iles et al., 2010a; Iles et al., 2010b; Al Ariss et al., 2014), a more progressive approach.

\section{Talent Employees in Concept}

Among the basic theoretical concepts of talent management it is possible to highlight strategic talent management, integrated talent management, global talent management or total quality management when applied to talent management.

Strategic talent management is defined by Collings and Mellahi (2009) as activities and processes which are related to the systematic identification the key positions, development of the talent pool, as well as the development of differentiated human resource architecture. This is all done in order to facilitate the match of the right employees with the right job, as well as to 
ensure their connection and commitment to the organisation. Silzer and Dowell (2010) add that this concept shows talent management to be a key organisational process ingrained in the whole organisation.

Integrated talent management is one of the holistic approaches, which is based on Avedon and Scholes (2010), for integrating talent on four main levels. This approach contains: business strategy, the human resources strategy, talent management processes and organizational culture is connected in one package.

Global talent management, according to Scullion et al. (2010), includes organizational processes connected to employee recruitment, selection, development and retention of the best employees in strategic positions in global perspective. This concept reflects the specifics of global strategic priorities, as well as those priorities in the national context.

Current trends in Human Resource [HR] management connect the terms Total Quality Management [TQM] and Talent Management [TM]. Stevens (2008) states that by using TQM it is possible to improve the problematic areas of TM. These problematic areas are commonly found in organizations and so the methods of dealing with may be perfected in the management of intellectual capital. The areas to be improved concern: succession planning, loss of key/top talents, the correct placement of employees, employee development and reducing employee turnover.

A discussion of this point is relevant regarding talent management in different cultural contexts (Meyers \& van Woerkom, 2014). In many western cultures, talent is commonly understood as an innate ability that leads to above-average performance in a specific domain (Tansley, 2011). In Japan, by contrast, talent denotes outstanding accomplishments that result from many years of training (Tansley, 2011). Combining the two tensions discussed above leads to four distinct talent philosophies: exclusive/stable; exclusive/developable; inclusive/stable; and inclusive/developable (see Fig. 1).

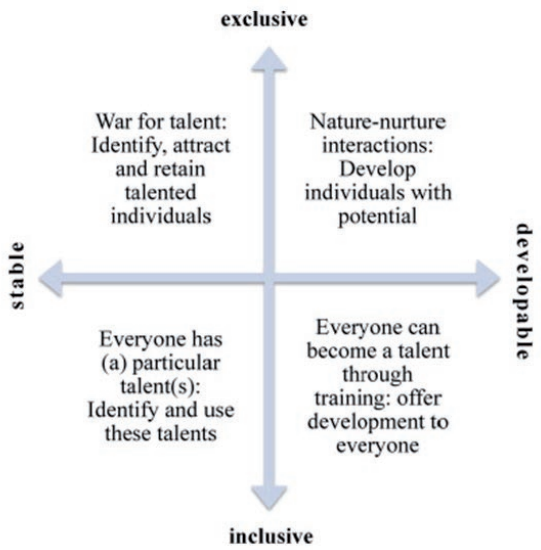

Fig. 1 - Talent Management Philosophies. Source: Meyers and van Woerkom (2014) 
Meyers and van Woerkom (2014) argue that these philosophies determine the nature of Human Resources Management [HRM] and talent management in practice, and consequently influence valuable outcomes such as employee well-being and performance.

Those concepts of talent management are broadly known, but may be considered with a lack of concrete descriptions of related activities focused on human capital and organizational processes. Therefore, an investigation into the practical use of the theoretical concepts of talent management philosophies is necessary. The survey presented in this paper is focused on the key competencies evaluated by organisation connected to talent management together with development possibilities perceived by Czech employees, and thus reveals the actual current approach taken by organisations to talent management philosophies.

Outcomes of most of published studies are very broad and generalised, while HRM practices bear no relation to the labour management activities in the company, and so do not lead to deeper understanding of talent management philosophies. This paper takes the study of this concept further, and focuses more sharply on the HRM practices; namely competencies evaluated by organizations and development possibilities perceived by employees within the organisation in order to define those which are specific and crucial for talent management and development.

Meyers and van Woerkom (2014), argue that these philosophies determine the nature of HRM and talent management in practice, and consequently influence valuable outcomes such as employee well-being and performance.

Research by National Institute for Education (2014) shows that, although demands placed by employers on individual competencies frequently depend upon a specific job description regardless of the size or industry in which organizations operate, employers both in industry and the service sector only moderately prefer professional to key competencies (knowledge, abilities and skills which seem necessary not only for success in the job market but also in everyday life). What is important are the key competencies that must be developed in talented employees. Employers are aware of this and that is why they consider key competencies comparable to professional competencies.

In the Czech companies, which were studied, these philosophies are rarely known and used. Instead, simple HRM practices are used. Therefore, their impact draws attention to the identification of usable talent management philosophies.

Because research carried out in the Czech Republic is currently skewed to the employer's viewpoint, research was undertaken comparing opinions on the talent management philosophies of both organizations (managers) and rank-and-file employees. In order to take the existing research a step forward, our study identifies philosophies considered key by employers (valuable for work in their organizations) along with areas in which these philosophies enable development, compared to evaluation of the philosophies by individual employees who assess the manner of development and their preferences for the future. The article also discusses methods used for talent development. 


\section{MATERIAL AND METHODS}

Our data were mainly extracted from secondary sources and our analysis and discussion is linked to outcome synthesis and the evaluation of international research results. The second part of this article analyses and evaluates the results of two primary surveys. The questionnaires were distributed using electronic questionnaire that automatically recorded and pre-categorized respondents' answers (CAWI method) and also by telephonic interviews (CATI method). The sample of organizations across the sectors in the Czech Republic was carried out as a random selection of organizations; the organizations were also selected in accordance with statistical data from the Czech Statistical Office while taking into account the structure of the organizations according to the sector of the economy (primary, secondary, tertiary), the size of the organization (small organizations of up to 50 employees, medium-sized organizations employing between 51 and 249 people and large organizations with more than 250 employees) and last but not least, the ownership of the organization. Only human resources specialists in the selected organizations were questioned (respondents worked as senior managers in the personnel department; or have been working as personnel specialists for 3 or more years and are university graduates in the human resources field). The respondents thus knew the used terms. Furthermore, the specific terms used were discussed and explained to informants.

The dataset was carried out by authors of the paper and only for purposes of the research. The data collection instrument included questions to measure the activities of talent management and development support in organization. The questions were designed based on theories (see theoretical background) and similar researches. The respondents' answers were classified according to identification questions that constituted the first part of the questionnaire. The measurement in the survey was derived from closed questions with one or several possible answers. Respondents' reactions to target statements and their attitudes to the given matter were restricted by offering a set of several statements. The extremes of the seven-point scale represented bipolar concepts of the evaluation dimension. All the questions were measured in a Likert type scale with verbal anchors in 1 (strongly agree) and 7 (strongly disagree) or, provided it was not possible to favour either of the sides, selected a median, neutral value (the median value was characterized by number 4). The scale permitted not only the specification of respondents' attitudes, but also their intensity.

The first survey was conducted in Czech organizations $(n=100)$ in 2014 and examined the area of talent management from the standpoint of organizations. A total of 512 organizations were contacted in the Czech Republic. The findings were finalised based on analysis of data obtained via questionnaire survey.

The data set comprised 100 organizations. The organizational structure was as follows:

- by economic sector: $1 \%$ primary sector, $26 \%$ secondary sector, $73 \%$ tertiary sector;

- by organization size (number of employees): $31 \%$ small, $28 \%$ medium, $41 \%$ large organizations;

- by organization assets: $79 \%$ Czech organizations, $4 \%$ Czech organizations with a foreign owner, $17 \%$ multinational organizations. 
The second survey was carried out using employees. From this point of view, results may be compared objectively because the opinions of both parties (management and employees) were determined. The employee data set comprised 125 employees. The employees were employed full time. Most employees, $82 \%$, have other than managerial positions. They are rank-and-file employees and $70 \%$ have no university education.

The employee respondents were structured as follows:

" employee age category: $11 \%$ - 20 to 24 years, $32 \%$ - 25 to 30 years, $35 \%$ - 31 to 40 years, $20 \%-41$ to 50 years and $2 \%$ over 51 years;

- employee professional experience: $10 \%$ - less than 1 year, $36 \%$ - more than 1 year and up to 5 years, $26 \%$ - more than 5 years but less than 10 years and $28 \%$ more than 10 years;

- employees work in the following industries: $1 \%$ primary sector, $18 \%$ secondary, $81 \%$ tertiary;

- employees work for organizations of size: $26 \%$ small, $29 \%$ medium, $45 \%$ large organizations;

" employees work for organizations owned by: $74 \%$ Czech organizations, $7 \%$ Czech organizations with a foreign owner, $19 \%$ multinational organizations.

The data were evaluated using the tools of descriptive statistics and the methods of comparison, induction, deduction, and synthesis. Descriptive statistics used to test the results included absolute and relative frequency, correlation analysis, and a non-parametric Pearson Chi-square test. Finally, the level of dependence was measured based on Cramer's V, using a scale devised by De Vaus (2002). Further analyses were based on multidimensional statistical methods - factor analysis (varimax rotation (Anderson, 2009); the Kaiser-Guttman rule was applied to select a group of significant factors. Following the recommendations of Anderson (2009), only determinants with an absolute value exceeding 0.3 were selected as significant for factor development; positive and negative dependency was further analysed in relation to its final benefits).

The following acronyms are used in the article: Talent Management = TM; Czech Statistical Office $=\mathrm{CSO}, \mathrm{CZ}=$ Czech Republic $; \mathrm{P}=$ precondition.

\section{RESULTS AND DISCUSSION}

This section contains the evaluation of the data, their interpretation, and recommendations. It focuses on the assessment of the current situation as regards the development of talented employees in Czech organizations; first from Czech organization perspective and second from the perspective of the Czech employees. The "Results" section is followed by the discussion and conclusions, which summarize the recommendations indicated by the results.

\subsection{Talent Management Philosophies: A Czech Organizations' Perspective}

The chief approach taken by organizations for evaluating employee education and development is to evaluate their competencies. As shown in Figure 2, the competencies monitored are varied. They may be classified as general/specific, inclusive/exclusive and static/dynamic. Many 
organizations have no conceptual plan for development and competencies are evaluated broadly regardless of specific positions. This can be considered an inclusive approach. In contrast, other activities such as leadership are rather exclusive. Czech organizations take a rather conservative approach to develop the talents of their employees. They develop them in generally recommended areas without any consideration for the specific individual's characteristics and related opportunities. In this case, it is rather a stable approach. Very few organizations consider talent an opportunity for continuous development and overcoming limitations. Figure 2 depicts the most frequently evaluated competencies in the organizations monitored.

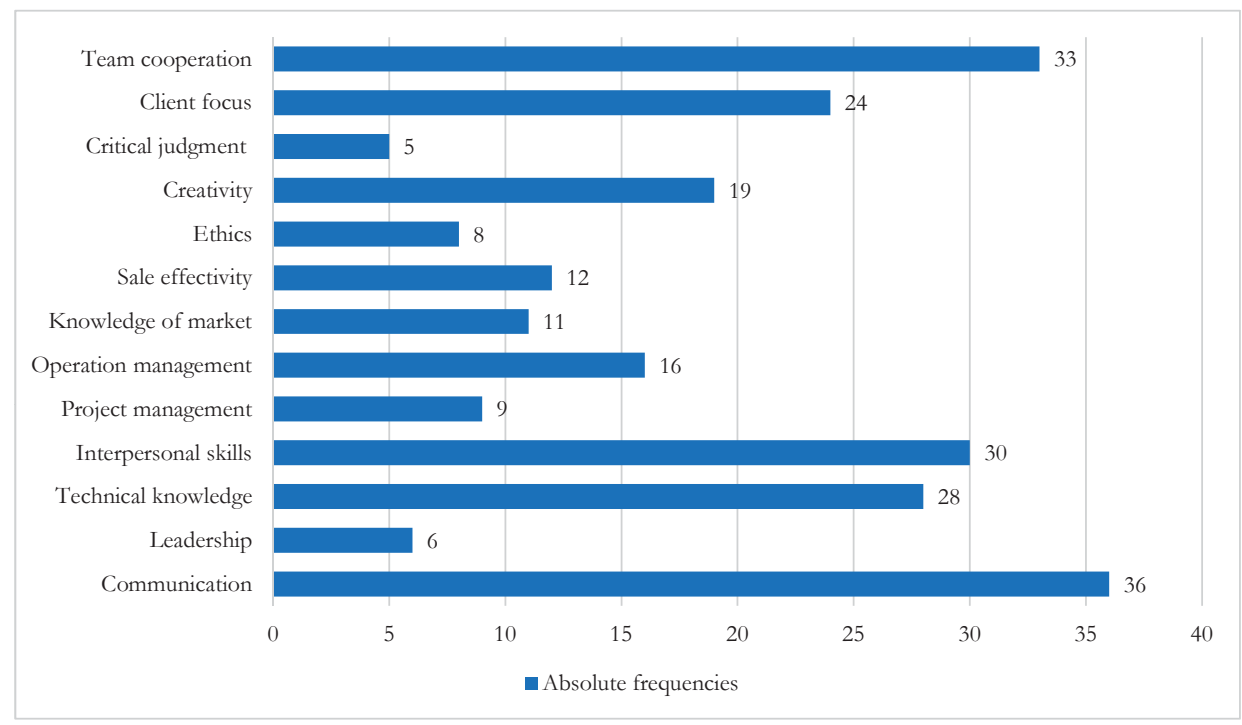

Fig. 2 - Evaluated competencies in the Czech Republic. Source: The survey

Note: interpersonal skills = employee's ability to get along with others while getting the job done; leadership = a process of social influence in which a person can enlist the aid and support of others in the accomplishment of a common task; communication $=$ exchange and flow of information and ideas from one employee to another; team cooperation $=$ achievement of manager-team dynamics.

The organizations monitored make significantly greater use of these competencies than any other competency monitored. Teamwork and communication are general competencies based upon the natural ability of people/employees to get along, function within a team and to communicate. These competencies are not difficult to attain through learning and development, even though some individuals find even this hard to do. Nevertheless, this is an inclusive approach to development and talent management, since these competencies are key for all employees and all have been trained in them. For other competencies, the approach is rather exclusive.

Other most frequently used competencies include working with people, customer orientation, and technical skills. These competencies are tied to a specific area of organization operations and employees must be sufficiently developed and educated in them to meet job requirements.

In contrast, ethical and leadership competencies are the least stressed. Czech organizations have had a long-term issue with ethical considerations (Linhartová, 2012). The same applies to a long- 
term concept for development and transfer of knowledge to another generation as a form of leadership (Linhartová \& Urbancová, 2012).

Concerning specific development methods, $54 \%$ of Czech Republic organizations use an effective combination of off-the-job/on-the-job development. Only $6 \%$ focus exclusively on offthe-job methods, primarily seminars (38\%), workshops (23\%) and lectures (23\%), and least on development centres $(1 \%)$. Unfortunately, organizations operating in the Czech Republic use this development method only sporadically, primarily in cases of foreign organizations or Czech organizations with foreign participation. Such organizations implement development programs for their employees in midlevel and top management. Other organizations combine methods that are more conservative. A key reason for lack of use of this method lies in the cost per participant per day (depending upon the number of evaluators). On average, it is CZK 6000 up to CZK 30,000 (approximately EUR 220 up to 1,100). A total of $12 \%$ of organizations prefer only on the job methods. They primarily make use of task delegation $(27 \%)$ and project work $(23 \%)$. Of job methods, job rotation is least preferred $(10 \%)$.

\subsection{Talent Management Philosophies: A Czech Employees‘ Perspective}

Focusing on the perception of employee development, education, and talent management from the point of view of the Czech employees, there is much room for improvement in Czech organizations. According to employees'perspective $43 \%$ of the organizations monitored actively develop employee competencies via talent management. In contrast, $52 \%$ do not deal with talent management at all or the respondents knew nothing about it. $5 \%$ of respondents were not sure whether their organizations engaged in talent management in any manner whatsoever. Most organizations that use talent management come from the tertiary sector $(60 \%)$ or are large organizations $(38 \%)$. Statistical testing (Chi-square test) determined that application of talent management in organizations in the Czech Republic does not depend upon organization size $(\mathrm{P}$-value $=0.649)$.

Figure 3 shows that employees most frequently included career growth and opportunity for further education and development ( $96 \%$ ) among reasons that affect the opportunity for development within an organization. Employees perceive opportunities for development and take part if career growth is offered to them or if they are directly offered educational and development activities.

The frequently indicated opportunities also included external offers for interesting jobs. This shows employees are ready to migrate outside their organizations. $68 \%$ of employees perceive external career and talent development as an opportunity and reason for moving on. It is paradoxical that some employees start to learn and develop only at when they wish to leave the original organization and apply their newly acquired skills, knowledge, and experience elsewhere. Therefore, organizations should focus on development possibilities on current job or making existing jobs more attractive to employees or offer opportunities to move up to another, higher or specialized position if employees aspire to them. If such an opportunity is known to exist, employees are willing to learn. If no such opportunity exists, it is likely employees will learn at the expense of their original organizations and then they will leave them. The costs incurred for the development process will thus not return. 


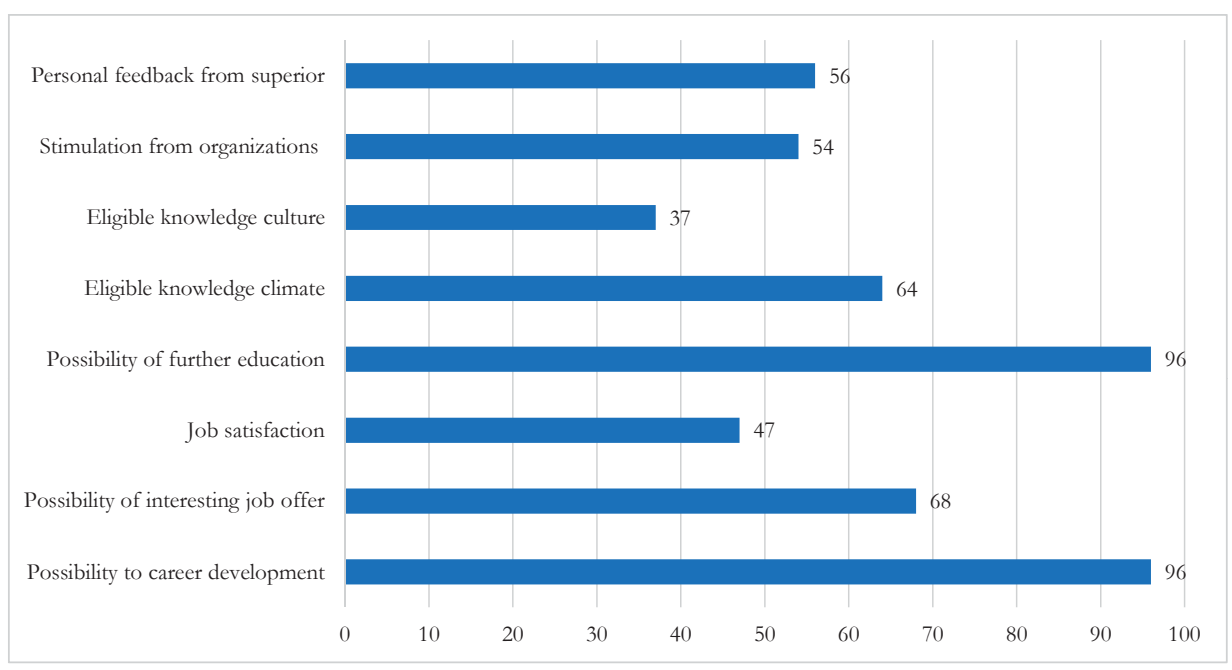

Fig. 3 - Employees perceive opportunities for development. Source: Own survey

Note: Organizational climate refers to atmosphere at workplace and organization culture refers to organizational rules, norms, way of work, team cooperation, type of communication, knowledge sharing and goal setting.

A suitable environment must be created for education and development initiated by employees themselves. Employees appreciate personal feedback from their supervisors (56\%), a suitable organizational climate $(64 \%)$, motivation from the organization $(54 \%)$ and a suitable organization culture $(37 \%)$.

As these results show, Czech employees wish to be supported in their development and motivated by their organization or direct supervisors. There is less room for their own initiative. Only 47 $\%$ of respondents indicated that their existing satisfaction at work is the reason for their further development, encouraging them to continue to take an active part in their own development in the future - so they enjoy a self-satisfaction and self-motivation from their own jobs.

From employees'perspective opportunities for development can be considered an exclusive approach. They see inclusive opportunities mainly outside the organization. Thus it also point at a rather conservative approach to develop talent. As mentioned in results of chapter 3.1, talent is developed in generally recommended areas without any consideration for the specific individual's characteristics and related opportunities. It is rather a stable approach.

Therefore, half of employees perceive organizations to work on talent management in line with the theory that employees should be supported in accordance with the company culture, strategy, and goals. Their percentage numbers oscillate around $50 \%$, which is not high.

The passivity shown by Czech employees when it comes to talent development and only partially active organizations is testified to by further research findings. Over the recent 12 months, $75 \%$ of employees took part in training. A further $24 \%$ did not take part in any training or education process. $1 \%$ were not sure. $81 \%$ of employees perceive the training to be useful, $17 \%$ claim it was not useful and $2 \%$ are not sure. 
Considering that employees are rather passive in terms of talent development and expect motivation from their organization, a number of organizations find themselves in a dead-end situation in which employees lack stimuli and talent development declines. In the worst case, employees receive another attractive offer outside their organization and develop only to be able to leave and apply for a more attractive job elsewhere.

\subsection{Talent Philosophies - Factor Analysis}

Furthermore, factor analysis was used in consequence to correlation matrix, which has shown significant relations between variables. Regarding overall medium till strong dependences between variables, constructed for the survey for the reason of their clear use in the construct, it was expected to find statistically significant factors. As shown in Table 1, factor analysis revealed 3 statistically significant factors. Such variables (statements of respondents) were chosen as significant to create resulted factor, whose value was 0.3 and higher (Anderson, 2009). Factors together explain $69.52 \%$ of behaviour of total construct.

Tab. 1 - Relations between factors

\begin{tabular}{|l|c|c|c|}
\hline Variable & Factor 1 & Factor 2 & Factor 3 \\
\hline ongoing development & 0.400 & 0.742 & -0.098 \\
\hline use of skills & 0.834 & 0.196 & 0.153 \\
\hline personal success & 0.781 & 0.396 & 0.144 \\
\hline organization supports development & 0.378 & 0.684 & 0.235 \\
\hline motivation for development & 0.264 & 0.087 & 0.684 \\
\hline awards for outstanding work outcomes & 0.088 & 0.618 & 0.361 \\
\hline work performance increase & 0.225 & 0.253 & 0.798 \\
\hline participation on development & -0.042 & 0.456 & 0.714 \\
\hline development is part of job & 0.336 & 0.686 & 0.324 \\
\hline \% of variance & 48.160 & 11.360 & 9.546 \\
\hline Name of the factor & Inclusive & $\begin{array}{c}\text { Inclusive - } \\
\text { developable }\end{array}$ & $\begin{array}{c}\text { Exclusive - } \\
\text { developable }\end{array}$ \\
\hline
\end{tabular}

Source: Author's survey

Note: Variables were shortened in the Table 1. Their original meaning is interpreted bellow in the results of the study.

The first factor (Factor 1) describes an inclusive and stable approach. Employees are supported by organization, using gain knowledge, skills and abilities. Employees are constantly developed giving the social status and personal success. Thus it is possible to summarize the factor describes an organizational culture which support development of all their employees. Knowledge are constantly developed and used at work process. Almost half of surveyed organizations (48.16 $\%$ ) behave in this manner. 
Factor number 2 revealed different type of philosophy. The second factor shows also possibilities to be developed in organization, organization support development on the job. Additionally, organization offer special rewards and awards or appreciation of superior outputs at work; employees in such organisation may compete in different competitions focused on work, projects and other concepts. Employees grouped by Factor 2 are also constantly developed and take part on development program periodically or on regular base. Described organisational environment is quite superior, supporting employees and profiting from their constant development. Total $11.36 \%$ of sample behaves in this manner.

The third factor (Factor 3) revealed developable approach of employees, who are motivated for development. It is characterized by possibility for such employee to be constantly part of development program. Moreover, development of an employee has straight impact on employees work. Factor 3 therefore describes exclusive and developable philosophy. This factor represents almost $10 \%$ of respondents.

Based on presented results of analyses we found three different talent management philosophies used in praxis of surveyed organizations. Almost half of sample use inclusive and stable philosophy, $11 \%$ inclusive - developable philosophy and $10 \%$ exclusive - developable philosophy. It is possible to summarize that all philosophies have its practical use. Organizations in studied sample mostly try to develop all employees (inclusive philosophy). On the other hand they differ in between stable and developable approach.

\subsection{Discussion}

Personal development of employees working for organizations is a seminal part of everyday life. Peter Ferdinand Drucker said, "Knowledge must be improved, challenged and increased constantly or it vanishes." (Brainyquote, 2014).

Although talent management as a term appeared in the Czech environment only in the late 1990s and early 2000s, it has become a key factor in the success experienced by organizations and research institutions across the Czech Republic. However, not all organizations possess sufficient funds, experts, time, etc. to put developmental procedures into practice.

In the current competitive environment, talented people are important in every field. Organizations can get a head start if they start looking for talented people while they are still at school; this is the case in many organizations in a number of European States. The most important steps organizations take in looking for talented workers include concretely defining talent; this is because the ambiguous meaning of the term complicates the situation in individual industries. Any definition of talent should come first and will differ for every organization. Organizations providing consultancy and production facilities differ in their talent requirements. Generally, talented people always have an area of key competencies and skills in common. Their high level is often a precondition for expert performance in the particular area, as confirmed by Königová et al. (2012). Analytical and syntactical abilities, emotional intelligence, the ability to collaborate and communication competencies are skills that must be developed and supported in talented employees. In order to prosper, working with talented individuals is considered a strategic policy for many organizations. 
Most large organizations in the CZ accept talent management as part of HR policy. Middle and top management usually agree that talent management may significantly resolve the lack of qualified employees in future. However, many Czech organizations do not see talent management a mechanism to resolve current issues. The vision is that talented management in $\mathrm{CZ}$ is mostly used only for reliable employees in leading positions, and is part of traditional compensation. This distances qualified employees even more from young talented people where knowledge transfer becomes an issue; hence, continuity of knowledge is not secured, which endangers organizations (Urbancová, 2012).

The economic crisis that struck organizations in the CZ severely between 2008 and 2014 represented a threat to existing and future talent management programs. Investment in talent hunting programs was limited and many young employees with good prospects were made redundant. The job market thus temporarily filled with talents that could not be purchased by Czech organizations. The layoffs particularly impacted R\&D employees. Currently, however, the situation is improving and investments into research and development have been on an upward trend.

Implementing talent management brings benefits to the organization and its strategic planning: Identification of employees who wish to progress and move the organization forward; organizations thus know in advance who is a good investment. Reduced turnover costs and costs of hiring new employees, with the attendant minimization of losses generated by hiring employees for key positions (Linhartová \& Urbancová, 2012; Königová et al. 2012; Vnoučková, 2013). Further, talent management creates new sources of income and new directions in business. Motivation on the part of talented employees is then reflected in their behaviour toward customers, increasing customer satisfaction and building and supporting the employer's brand.

As McDonnell et al. (2010), explained; the organizations have a problem, as it can make managers fail to understand where the talent resides within their organizations, and where they can find the human capital required to implement the designated business strategies.

The results in the Czech Republic show that the current disadvantage of organizations is that most of them focus only on selected individuals; the so-called "talents"; while the others are undervalued. These people lose their motivation and job performance declines. It should not be considered to be a good approach. Organizations must focus on the inclusion of talent management.

\section{CONCLUSION}

The theoretical contribution of this study has been to present key approaches of talent management, and their classification; and to present the key philosophies behind talent management. Because talent management is often confused with the learning process or succession in practice, key terms and approaches present in talent management and their conceptual basis should be clarified. The chief approaches in talent management and the differences in the underlying concepts may be classified as exclusive/inclusive talent management and a static/dynamic understanding of talent. Results of the research carried out in Czech organizations have been analysed keeping this classification in mind. 
The practical contribution of the article is to present the results of research showing the situation in talent management in the Czech Republic. Results of analyses revealed different talent management philosophies used in praxis. Almost half of sample use inclusive and stable philosophy, $11 \%$ inclusive and developable philosophy and 10\% exclusive and developable philosophy. All theoretical philosophies are used in praxis. Organizations represented by studied sample mostly try to develop all employees (inclusive philosophy). On the other hand they differ in between stable and developable approach.

More than half of studied organizations have no conceptual plan for talent management; and competencies are evaluated broadly regardless of specific positions. This characterizes an inclusive approach. In contrast, other activities such as leadership are rather exclusive. Studied Czech organizations take a rather conservative approach to develop the talents of their employees. Employees are mostly developed in generally recommended areas without any consideration for the specific individual's characteristics and related opportunities. In this case, it is rather a stable approach. Very few organizations (less than 10\%) consider talent an opportunity for continuous development and overcoming limitations.

It is important, however, to recognise the limitations of this study. First, analysis of this paper's outcomes would particularly interest practitioners. The present findings provide a basis for future hypotheses and research in this area. Second, methodological issues need to be addressed. There is the possibility of sample bias owing to the voluntary involvement of participants and this necessitates caution in generalising these results to a broader sample of the working population. This issue should not, however, be allowed to discourage further research in this area.

Aside from this study, there are several promising avenues for further research. It would be useful to know the impact on life-long development and there should be an investigation of the longer-term impact of learning in organizations.

Acknowledgement:

This contribution is a follow-up to the project of University of Economics and Management in Prague.

\section{References}

1. Abbas, M., Raja, U., Darr W., \& Bouckenooghe, D. (2014). Combined Effects of Perceived Politics and Psychological Capital on Job Satisfaction, Turnover Intentions and Performance. Journal of Management, 40 (7), 1813-1830. DOI: 10.1177/0149206312455243

2. Adler, P. S., \& Kwon, S. W. (2002). Social capital: Prospects for a new concept. Academy of Management Review, 27 (1), 17-40. DOI: 10.5465/AMR.2002.5922314

3. Anderson, V. (2009). Research Methods in Human Resource Management. London: Chartered Institute of Personnel Development.

4. Al Ariss, A., Cascio, W. A., \& Paauwe, J. (2014). Talent management: Current theories and future research directions. Journal of World Business, 49 (2), 173-179. DOI: 10.1016/ j.jwb.2013.11.001

5. Avedon, M. J., \& Scholes, G. (2010). Building competitive advantage through integrated talent management. In Silzer R., \& Dowell B. E. (Eds.), Strategy-driven talent management: A leadership imperative, (pp.73-119). San Francisco, Josey-Bass. 
6. Becker, B., \& Gerhart, B. (1996). The impact of human resource management on organizational performance: Progress and prospects. Academy of Management Journal, 39 (4), 779-801

7. Buckingham, M., \& Vosburgh, R. M. (2001). The 21st century human resources function: It's the talent, stupid! Human Resource Planning, 24, 17-23.

8. Burt, R. S. (1997). The contingent value of social capital. Administrative Science Quarterly, 42 (2), 339-365. DOI: $10.2307 / 2393923$

9. Boudreau, J. W., \& Ramstad, P. M. (2005). Talentship, talent segmentation, and sustainability: A new HR decision science paradigm for a new strategy definition. Human Resource Management, 44, 129-136. DOI: 10.1002/hrm.20054

10. Collings D. G., \& Mellahi K. (2009). Strategic talent management: A review and research agenda. Human Resource Management Review, 19 (4), 304-313 doi:10.1016/j.hrmr.2009.04.001

11. De Vaus, D. (2002). Surveys in Social Research. London: Routledge/Taylor and Francis.

12. Farndale, E., Scullion, H., \& Sparrow, P. (2010). The role of the corporate HR function in global talent management. Journal of World Business, 45 (2), 161-168. doi:10.1016/ j.jwb.2009.09.012

13. Gelens, J., Hofmans, J., Dries, N., \& Pepermans, R. (2014). Talent management and organisational justice: Employee reactions to high potential identification. Human Resource Management Journal, 24 (2), 159-175. DOI: 10.1111/1748-8583.12029

14. Chhabra, N. L. \& Sharma, S. (2014). Employer branding: Strategy for improving employer attractiveness. International Journal of Organizational Analysis, 22 (1), 48-60. DOI: 10.1108/ IJOA-09-2011-0513

15. Iles, P., Chuai, X., \& Preece, D. (2010a). Talent management and HRM in multinational companies in Beijing: Definitions, differences and drivers. Journal of World Business, 45 (2), 179-189. DOI: $10.1016 /$ j.jwb.2009.09.014

16. Iles, P., Preece, D., \& Chuai, X. (2010b). Talent management as a management fashion in HRD: Towards a research agenda. Human Resource Development International, 13 (2), 125-145. DOI: $10.1080 / 13678861003703666$

17. Joyce, W. F., \& Slocum, J. W. (2012). Top management talent, strategic capabilities, and firm performance. Organizational Dynamics, 41 (3), 183-193. DOI: 10.1016/j.orgdyn.2014.11.006

18. Katcher, B. L., \& Snyder, A. (2007). 30 Reasons Employees Hate Their Managers: What Your People May Be Thinking and What You Can Do About It. New York: AMACOM.

19. Königová, M., \& Urbancová, H. (2013). Evaluation of factors influencing Human Resource Branding in the Czech Republic and the Slovak Republic. International Journal of Marketing and Human Resource Management, 4 (1), 59-67.

20. Königová, M., Urbancová, H., \& Fejfar, J. (2012). Identification of Competencies in Knowledge-Based Organizations. Journal of Competetiveness, 4 (1), 129 - 142. DOI: 10.7441/ joc. 2012.01 .10

21. Lewis, R. E., \& Heckman, R. J. (2006). Talent management: A critical review. Human Resource Management Review, 16 (2), 139-154. DOI: 10.1016/j.hrmr.2006.03.001 
22. Linhartová, L. (2012). Variability of Employees' Behaviour during Disaffection. Economic Journal, 60 (1), 83-97.

23. Linhartová, L., \& Urbancová, H. (2012). Results of analysis of employee mobility: factors affecting knowledge continuity. Acta Universitatis Agriculturae et Silviculturae Mendelianae Brunensis, LX (4), 235-244. DOI: 10.11118/actaun201260040235

24. McDonnell A., Lamare R., Gunnigle P., \& Lavelle J. (2015). Developing tomorrow's leaders: Evidence of global talent management in multinational companies. Business Research Quarterly, 45, 150-160.

25. Meyers, M. C., \& van Woerkom, M. (2014). The influence of underlying philosophies on talent management: Theory, implications for practice, and research agenda. Journal of World Business, 49 (2), 192-203. DOI: 10.1016/j.jwb.2013.11.003

26. National Institute for Education (2014). Online. Retrieved from http://www.infoabsolvent. cz/Temata/Clanek Absolventi/4-1-03/Dalsi-kompetence-ktere-zamestnavatelepotrebuji/26.

27. Scullion, H., Collings, D. G., \& Caligiuri, P. (2010). Global talent management. Journal of World Business, 45 (2), 105-108. doi:10.1016/j.jwb.2009.09.011

28. Seibert, S. E., Kraimer, M. L., \& Liden, R. C. (2001). A social capital theory of career success. Academy of Management Journal, 44 (2), 219-237. doi:10.2307/3069452

29. Silzer R. F., \& Dowell B. E. (2010). Strategy-driven talent management: a leadership imperative. San Francisco, Jossey-Bass.

30. Smilansky, J. (2005). The Systematic Management of Executive Talent. London: Hydrogen.

31. Sonnenberg, M., van Zijderveld, V., \& Brinks, M. (2014). The role of talent-perception inkongruence in effective talent management. Journal of World Business, 49 (2), 272-280. doi:10.1016/j.jwb.2013.11.011

32. Stevens, H. P. (2008). Total quality management now applies to managing talent. The Journal for Quality and Participation, 31, 15-18.

33. Tansley, C. (2011). What do we mean by the term "talent" in talent management? Industrial and Commercial Training, 43, 266-274. DOI: 10.1108/00197851111145853

34. Urbancova, H. (2012). The Process of Knowledge Continuity Ensuring. Journal of Competitiveness, 4(2), 38-48. doi:10.7441/joc.2012.02.03

35. Vnoučková, L. (2014). Employee development in human resource management. Proceedings of the 8th International Days of Statistics and Economics, Prague: University of Economics.

36. Walker, A. (1999). The Emergence of Age Management in Europe. International Journal of Organisational Behaviour. 10 (1), 685-697.

37. Yost, P. R., \& Chang, G. (2009). Everyone is equal, but some are more equal than others. Industrial and Organizational Psychology: Perspectives on Science and Practice, 2, 442-445.

38. Zahorsky, D. (2010). Fighting Employee Turnover Costs: Reduce Employee Turnover. Online. Retrieved from http://sbinformation.about.com/od/hiringfiring/a/ reduceturnover.htm. 


\section{Contact information}

Ing. Hana Urbancová, Ph.D.

University Economics and Management, Department of Human Resources

Nárožní 2600/9a, 158 00, Prague 5, Cžech Republic

Email:hana.urbancova@vsem.cz.

Ing. Lucie Vnouckková, Ph.D.

University Economics and Management, Department of Human Resources

Nárožni 2600/9a, 158 00, Prague 5, Cžech Republic

Email:lucie.vnouckova@vsem.cr. 